\title{
Sunitinib in combination with trastuzumab for the treatment of advanced breast cancer: activity and safety results from a phase II study
}

Thomas Bachelot ${ }^{1}$, Jose A Garcia-Saenz ${ }^{2}$, Sunil Verma ${ }^{3}$, Maya Gutierrez ${ }^{4}$, Xavier Pivot ${ }^{5}$, Mark F Kozloff 6 , Catherine Prady ${ }^{7}$, Xin Huang ${ }^{8}$, Reza Khosravan ${ }^{8}$, Zhixiao Wang ${ }^{9,12}$, Rossano Cesari ${ }^{10}$, Vanessa Tassell ${ }^{8,13}$, Kenneth A Kern ${ }^{8}$, Jean-Yves Blay ${ }^{1,14^{*}}$ and Ana Lluch ${ }^{11}$

\begin{abstract}
Background: This phase II study evaluated the efficacy and safety/tolerability of sunitinib plus trastuzumab in patients with HER2-positive advanced breast cancer (ABC).

Methods: Eligible patients received sunitinib $37.5 \mathrm{mg} /$ day and trastuzumab administered either weekly (loading, $4 \mathrm{mg} / \mathrm{kg}$; then weekly $2 \mathrm{mg} / \mathrm{kg}$ ) or 3-weekly (loading, $8 \mathrm{mg} / \mathrm{kg}$; then 3-weekly $6 \mathrm{mg} / \mathrm{kg}$ ). Prior trastuzumab and/or lapatinib treatment were permitted. The primary endpoint was objective response rate (ORR).

Results: Sixty patients were enrolled and evaluable for safety; 57 were evaluable for efficacy. The majority of patients (58\%) had received no prior chemotherapy in the metastatic setting. The ORR was 37\%; the clinical benefit rate (CBR; percent objective response plus stable disease $\geq 24$ weeks) was 56\%. Among patients who were treatment-naïve or had received only adjuvant therapy, the ORR was 44\% and the CBR was 59\%. Overall, median overall survival had not been reached and the 1-year survival rate was $91 \%$. The majority of adverse events (AEs) were mild to moderate in severity. Forty percent of patients experienced AEs related to measured left ventricular ejection fraction (LVEF) declines, which occurred more frequently in patients who had received prior anthracycline treatment. Ten percent of patients exhibited symptoms related to LVEF declines. One patient died on study from cardiogenic shock. Antitumor response and several safety parameters appeared to correlate with sunitinib exposure.

Conclusions: Sunitinib plus trastuzumab demonstrated antitumor activity in patients with HER2-positive ABC, particularly those who were treatment-naive or had only received prior adjuvant treatment. Sunitinib plus trastuzumab had acceptable safety and tolerability in patients with HER2-positive ABC who had not received prior anthracycline therapy.
\end{abstract}

Trial registration: NCT00243503

Keywords: Sunitinib, Trastuzumab, Advanced breast cancer

\footnotetext{
* Correspondence: jean-yves.blay@lyon.unicancer.fr

'EORTC, Soft Tissue and Bone Sarcoma Group, Centre Léon-Bérard and

Université Claude Bernard, Lyon, France

${ }^{14}$ Léon Bérard Comprehensive Cancer Centre, Université Claude Bernard

Lyon I, 28 rue Laennec, F-69008 Lyon, France

Full list of author information is available at the end of the article
} 


\section{Background}

Trastuzumab is approved in combination with taxanes for first-line treatment and as monotherapy for secondline treatment of HER2-positive metastatic breast cancer (MBC). Objective response rates (ORRs) for patients with $\mathrm{MBC}$ receiving trastuzumab monotherapy were $26 \%$ in the first-line setting [1] and approximately $15 \%$ in the second-line setting [2,3]. However, resistance to trastuzumab alone or in combination with chemotherapy generally develops within 1 year of initiating treatment $[1,2,4-6]$.

Sunitinib malate $\left(\mathrm{SUTENT}^{\circ}\right.$; Pfizer Inc., New York, NY, USA), an oral, multitargeted tyrosine kinase inhibitor (TKI) of vascular endothelial growth factor receptors (VEGFRs), platelet-derived growth factor receptors (PDGFRs), and other receptor tyrosine kinases [7-12], is approved multinationally for the treatment of advanced renal cell carcinoma (RCC), imatinib-resistant/-intolerant gastrointestinal stromal tumor (GIST), and progressing metastatic pancreatic neuroendocrine tumor. In a phase II study of heavily pretreated patients with $\mathrm{MBC}(\mathrm{N}=64)$, single-agent sunitinib at $50 \mathrm{mg} /$ day on Schedule $4 / 2$ (4 weeks on treatment followed by 2 weeks off treatment) demonstrated antitumor activity (ORR, 11\%; clinical benefit rate [CBR; percent objective responses plus stable disease (SD) $\geq 24$ weeks], 16\%) [13]. In some patients in this trial, tumor regrowth was observed during the period off treatment following initial shrinkage on treatment. Sunitinib administration at $37.5 \mathrm{mg}$ on a continuous daily dosing (CDD) schedule has also been found to be active and feasible in RCC, GIST, and pancreatic neuroendocrine tumor [14-17], and was used subsequently in sunitinib trials in MBC.

Preclinical and clinical data support the rationale that concurrent inhibition of VEGF and HER2 signaling may be more efficacious than inhibition of either target alone [18-21]. VEGF may in part mediate the aggressive breast cancer $(\mathrm{BC})$ phenotype associated with HER2 overexpression $[18,19]$, and constitutively active HER2 has been shown to increase VEGF protein synthesis levels in human BC cells [20].

In a mouse model of HER2-amplified $\mathrm{BC}$, sunitinib plus trastuzumab elicited a $75-80 \%$ greater decrease in tumor volume than either agent alone (Pfizer Inc., data on file). A phase II study of the anti-VEGF monoclonal antibody bevacizumab and trastuzumab as first-line therapy for HER2-positive MBC yielded an ORR of 46\% [21], which compared favorably with results obtained with trastuzumab alone in other studies $[1,22]$. Preliminary results of a phase III study also suggested that addition of bevacizumab to the combination of trastuzumab and docetaxel in a similar setting leads to modest improvements in clinical outcomes [23]. Since preclinical studies had demonstrated that dual inhibition of the VEGF and PDGF signaling pathways provide greater antitumor activity than inhibition of either pathway alone [24,25], it was hypothesized that the addition of the multitargeted TKI sunitinib to a trastuzumab-based regimen would be especially efficacious.

The current phase II study evaluated the efficacy and safety/tolerability of sunitinib on a CDD schedule in combination with trastuzumab, weekly or every 3 weeks, in patients with HER2-positive advanced (metastatic or locally recurrent) $\mathrm{BC}(\mathrm{ABC})$. The primary objective of the study was to determine the antitumor activity of the combination. Sunitinib is not approved for $A B C$, and Pfizer did not submit a request for regulatory review of sunitinib in $\mathrm{ABC}$ by the FDA or other regulatory bodies. This decision was made following the findings that sunitinib did not meet primary study endpoints in phase III trials in this setting [26-29].

\section{Methods}

\section{Patient selection}

Key inclusion criteria: Eligible patients were female aged $\geq$ 18 years with histologically or cytologically proven, unresectable, locally recurrent or metastatic HER2-positive BC and measurable disease based on Response Evaluation Criteria in Solid Tumors (RECIST) [30]. The study also included patients who may have had prior trastuzumab and/or lapatinib treatment in the neoadjuvant, adjuvant, or metastatic disease setting, or prior treatment with hormone therapy in the adjuvant and/or advanced disease setting. Patients were required to have an Eastern Cooperative Oncology Group performance status of 0 or 1 with adequate organ function (including left ventricular ejection fraction $[\mathrm{LVEF}] \geq 55 \%$ ) and resolution of all acute toxic effects of prior therapy or surgical procedures to National Cancer Institute Common Terminology Criteria for Adverse Events, version 3.0 (NCI CTCAE v3.0) grade $\leq 1$ (except alopecia).

Key exclusion criteria: Patients with prior treatment with more than one regimen of cytotoxic therapy for advanced disease or prior treatment with sunitinib (or trastuzumab if there was a history of hypersensitivity reactions) were excluded, as were patients with prior systemic therapy, radiation therapy, or surgery $\leq 3$ weeks before the first dose of study treatment (prior palliative radiotherapy to non-target metastatic lesions was permitted). Brain metastases and cardiovascular disease or uncontrolled hypertension were also exclusion criteria.

This study was conducted in accordance with the International Conference on Harmonisation Good Clinical Practice guidelines, the Declaration of Helsinki, and applicable local regulatory requirements and laws. Approval from the institutional review board (IRB) or independent ethics committee (IEC) of each participating center was required. All patients gave written, informed consent prior to enrollment. 


\section{Study design and dosing}

Originally developed using a randomized, placebocontrolled design (control arm: trastuzumab plus placebo; test arm: trastuzumab plus sunitinib), the study was subsequently changed to an open-label, single-arm design in response to evolving standards of care in which single-agent trastuzumab was considered suboptimal for patient treatment. As such, with the control arm consisting of trastuzumab as the only active agent, patient recruitment was limited. Under these circumstances, the control arm was removed, while the test arm (trastuzumab plus sunitinib) was retained in the revised single-arm study. The primary endpoint was ORR based on RECIST. Secondary endpoints included duration of tumor response, CBR, progression-free survival (PFS), overall survival (OS), safety, pharmacokinetics (PK), and patient-reported outcomes (PROs). The final protocol was approved by the IRB and/or IEC at each participating center.

\section{Study-drug administration}

Sunitinib $37.5 \mathrm{mg}$ was taken orally once daily in the morning, without regard to meals; a cycle was considered to be 4 weeks. Patients were monitored for toxicity; 1-week dosing interruptions were permitted for doselimiting toxicities. Dose reduction to $25 \mathrm{mg} /$ day was permitted for recurring grade $3 / 4$ toxicity. Dose escalation to $50 \mathrm{mg} /$ day was permitted after two treatment cycles with minimal treatment-related side effects. Further dose titration was permitted in subsequent cycles based on tolerability.

Trastuzumab was administered intravenously starting on cycle 1 , day 1 (C1D1), on either a weekly schedule (loading dose, $4 \mathrm{mg} / \mathrm{kg}$ on day 1 ; maintenance dose, $2 \mathrm{mg} / \mathrm{kg}$ on days $1,8,15$, and 22 every 4 weeks) or a 3 -weekly schedule (loading dose, $8 \mathrm{mg} / \mathrm{kg}$ on day 1; maintenance dose, $6 \mathrm{mg} /$ kg every 3 weeks), as a previous study had shown no difference in efficacy or safety between the two schedules [22]. No dose modification was permitted, but dosing could be delayed depending on tolerability.

\section{Study assessments}

Tumor assessments were performed using computed tomography or magnetic resonance imaging at baseline and every 8 weeks, and evaluated by the investigator using RECIST. Objective responses were confirmed $\geq 4$ weeks after initial documentation.

Safety was evaluated at regular intervals by monitoring adverse events (AEs; NCI CTCAE v3.0), hematology, and blood chemistry, and by physical examinations. QTc intervals were monitored using triplicate 12-lead electrocardiograms. LVEF was assessed using multigated acquisition or echocardiogram scanning at screening, on day 1 of odd-numbered treatment cycles beginning with
C3, as clinically indicated, and when treatment was discontinued.

Blood samples were collected pre-dose on C3D1 and C5D1 to evaluate trough concentrations of sunitinib and the active metabolite SU12662 using a validated, sensitive, and specific liquid chromatography-tandem mass spectrometric method (Bioanalytical Systems Inc; Lafayette, IN, USA) with acceptable accuracy and precision of quality control samples for sunitinib $(0.7-1.7 \%$ and $\leq 6.6 \%$, respectively) and SU12662 ( $-1.5 \%$ to $1.3 \%$ and $\leq 8.0 \%)$.

PROs were assessed using the self-administered European Organisation for Research and Treatment of Cancer Quality of Life Questionnaire C30 (EORTC QLQ-C30) and the related BC module BR23. EORTC QLQ-C30 assesses global health status, five functional domains (physical, role, cognitive, emotional, and social), eight symptom domains (fatigue, pain, nausea, appetite loss, constipation, diarrhea, dyspnea, and insomnia), and financial difficulties. BR23 assesses disease-related symptoms. Significant change was defined as both a clinically meaningful change of $\geq 10$ points (minimum important difference) [31] and a 95\% confidence interval (CI) for change from baseline not containing zero. Questionnaires were completed by patients on day 1 of each odd-numbered treatment cycle and at the end of treatment or withdrawal from the study.

\section{Statistical analysis}

The historical trastuzumab ORR was assumed to be $\leq 20 \%$ [1-3] and the predicted ORR for sunitinib plus trastuzumab to be $\geq 33 \%$. A sample size of $\geq 53$ was required to have $80 \%$ power at a $10 \%$ significance level to detect a $13 \%$ improvement in ORR. The lower bound of the 95\% CI of the ORR was required to be $>13 \%$ to reject the null hypothesis that the ORR of sunitinib plus trastuzumab was no different than that of the historical single-agent trastuzumab ORR.

The intention-to-treat population was the primary population for the evaluation of efficacy endpoints and patient characteristics. Exact two-sided 95\% CIs for the ORR and CBR were calculated using a method based on the $\mathrm{F}$ distribution. Time-to-event endpoints were summarized using the Kaplan-Meier method. One-year survival probability was estimated using the Kaplan-Meier method, with a two-sided 95\% CI calculated for the log using a normal approximation and then back-transformed to give a $\mathrm{CI}$ for the 1-year survival probability itself.

Steady-state dose-corrected trough plasma sunitinib concentrations were derived using data from patients who had taken sunitinib for $\geq 10$ consecutive days by correcting observed concentrations in patients who underwent dosing modifications based on the $37.5-\mathrm{mg}$ starting dose (starting dose $\div$ actual dose).

PRO data analysis was limited to the first seven cycles, in which there were $\geq 10$ patients. 


\section{Results}

\section{Patient characteristics}

Sixty patients with median age of 54 years (range 31-81) and ECOG PS score of $0 / 1$ in $52 / 58 \%$, respectively, were enrolled in the study at 17 centers across five countries between May 2006 and July 2008: six on the original protocol and 54 under the amended open-label design. Patient demographics and baseline characteristics are shown in Table 1 . There were 33 subjects (55\%) who were estrogen receptor-positive and 22 subjects (37\%) who were progesterone receptor positive. All subjects

Table 1 Patient characteristics at baseline

\begin{tabular}{|c|c|}
\hline Characteristic & n (\%) \\
\hline Patients receiving treatment & $60(100)$ \\
\hline Median age (range), years & $54(31-81)$ \\
\hline \multicolumn{2}{|l|}{ ECOG PS } \\
\hline 0 & $31(52)$ \\
\hline 1 & $29(48)$ \\
\hline \multicolumn{2}{|l|}{ Disease stage } \\
\hline Locally recurrent & $2(3)$ \\
\hline Metastatic & $58(97)$ \\
\hline \multicolumn{2}{|l|}{ Histologic type } \\
\hline Ductal & $51(85)$ \\
\hline Ductal and lobular & $1(2)$ \\
\hline Ductal and other & $1(2)$ \\
\hline Lobular & $3(5)$ \\
\hline Other & $4(7)$ \\
\hline \multicolumn{2}{|l|}{ Receptor status } \\
\hline Estrogen receptor-positive & $33(55)$ \\
\hline Progesterone receptor-positive & $22(37)$ \\
\hline HER2-positive* & $60(100)$ \\
\hline Prior systemic therapy & $44(73)$ \\
\hline Anthracycline + trastuzumab or lapatinib & $26(43)$ \\
\hline Anthracycline only & $11(18)$ \\
\hline Trastuzumab only & $4(7)$ \\
\hline Lapatinib only & $2(3)$ \\
\hline Other & $1(2)$ \\
\hline No prior systemic therapy & $16(27)$ \\
\hline \multicolumn{2}{|l|}{ Prior chemotherapy in metastatic setting } \\
\hline Yes & $25(42)$ \\
\hline No & $35(58)$ \\
\hline \multicolumn{2}{|l|}{ Location of disease } \\
\hline Regional or distant lymph node & $35(58)$ \\
\hline Lung & $27(45)$ \\
\hline Bone & $25(42)$ \\
\hline Liver & $24(40)$ \\
\hline
\end{tabular}

Abbreviation: ECOG PS Eastern Cooperative Oncology Group performance status. *IHC 3+: 52 (87\%); IHC 2+ 6 (10\%); FISH+: 22 (37\%). were HER2 positive by either FISH or IHC. The majority of patients (58\%) had received no prior chemotherapy in the metastatic setting.

\section{Treatment received}

Fifty-seven patients received the sunitinib-trastuzumab combination, making them evaluable for efficacy. Three patients received only trastuzumab. All 60 patients were evaluable for safety/tolerability. By data cut-off (October 2010), two patients had completed the study after receiving 18 months of study treatment and the remaining 58 patients had discontinued treatment: 44 due to disease progression, 11 due to AEs, and one each to death, consent withdrawal, and other (unspecified) reasons. Median treatment duration was 3.9 months (range: 0.5-15.7). Among the 57 patients who received the sunitinib-trastuzumab combination, most (63\%) had at least one sunitinib dosing interruption, with a median length of interruption of 8 days (range: 4-46). The sunitinib dose was reduced to $25 \mathrm{mg}$ in 22 patients (39\%) and subsequently to $12.5 \mathrm{mg}$ in three patients (5\%). Among the 60 patients who received trastuzumab, dosing was delayed by $\geq 1$ week in 18 patients $(30 \%)$. The median relative dose intensity was $72 \%$ (range: $47-127 \%$ ) for sunitinib and $96 \%$ (range: $60-122 \%$ ) for trastuzumab.

\section{Efficacy}

The confirmed ORR in the efficacy-evaluable population was $37 \%$, with a CBR of $56 \%$ (Table 2). The median duration of response was 5.9 months (95\% CI: 5.2-7.6). The majority of confirmed responses (71\%; $15 / 21$ patients) were reported among patients who were treatment-naïve or had received only adjuvant therapy. For this group, the ORR was $44 \%$ and the CBR was 59\%. The ORR was numerically higher among patients with visceral versus non-visceral disease ( $44 \%$ vs. $19 \%$, respectively) and among those with estrogen-receptor-negative versus -positive disease ( $41 \%$ vs. $33 \%)$. Overall, the majority of patients (43/57 evaluable patients, $75 \%$ ) had reductions in tumor size over the course of the study (Figure 1A).

At a median duration of follow-up of 24.4 months (95\% CI: 24.2-24.9), median PFS was 6.4 months (Figure 1B). Median OS had not yet been reached (Figure 1C); the 1-year survival rate was 91\% (95\% CI: 80-96\%).

\section{Safety}

The most commonly reported non-hematologic AEs of any cause were fatigue/asthenia (75\%), diarrhea (60\%), and stomatitis/related oral disorders (53\%; Table 3). The most common non-hematologic grade 3 AEs were fatigue/ asthenia (20\%), hypertension (13\%), and decreased appetite $(7 \%)$. There were six non-hematologic grade 4 AEs (LVEF decline, pulmonary embolism, hyponatremia, multi-organ failure, aspartate aminotransferase 
Table 2 Summary of tumor response with sunitinib plus trastuzumab

\begin{tabular}{|c|c|c|c|c|c|c|c|}
\hline \multirow{3}{*}{$\begin{array}{l}\text { Response } \\
\text { parameter }\end{array}$} & \multicolumn{7}{|c|}{ n (\%) } \\
\hline & $\begin{array}{c}\text { All } \\
\text { patients }\end{array}$ & $\begin{array}{l}\text { Treatment-naïve or prior } \\
\text { adjuvant treatment* only }\end{array}$ & $\begin{array}{l}\text { Prior first-line } \\
\text { treatment* }\end{array}$ & $\begin{array}{l}\text { Visceral } \\
\text { disease }^{\dagger}\end{array}$ & $\begin{array}{l}\text { Non-visceral } \\
\text { disease }\end{array}$ & $\begin{array}{c}\text { Estrogen-receptor } \\
\text { positive }\end{array}$ & $\begin{array}{c}\text { Estrogen-receptor } \\
\text { negative }\end{array}$ \\
\hline & $\overline{(n=57)}$ & $(n=34)$ & $(n=23)$ & $\overline{(n=41)}$ & $(n=16)$ & $(n=30)$ & $(n=27)$ \\
\hline Complete response & $2(4)$ & $2(6)$ & 0 & $1(2)$ & $1(6)$ & $2(7)$ & 0 \\
\hline Partial response & $19(33)$ & $13(38)$ & $6(26)$ & $17(41)$ & $2(13)$ & $8(27)$ & $11(41)$ \\
\hline Stable disease & $21(37)$ & $10(29)$ & $11(48)$ & $15(37)$ & $6(38)$ & $13(43)$ & $8(30)$ \\
\hline 24 weeks & $11(19)$ & $5(15)$ & $6(26)$ & $6(15)$ & $5(31)$ & $6(20)$ & $5(19)$ \\
\hline Objective response & $21(37)$ & $15(44)$ & $6(26)$ & $18(44)$ & $3(19)$ & $10(33)$ & $11(41)$ \\
\hline $95 \%$ exact $\mathrm{Cl}$ & $24-51$ & $27-62$ & $10-48$ & $28-60$ & $4-46$ & $17-53$ & $22-61$ \\
\hline Clinical benefit ${ }^{\ddagger}$ & $32(56)$ & $20(59)$ & $12(52)$ & $24(59)$ & $8(50)$ & $16(53)$ & $16(59)$ \\
\hline $95 \%$ exact $\mathrm{Cl}$ & $42-69$ & $41-75$ & $31-73$ & $42-74$ & $25-75$ & $34-72$ & $39-78$ \\
\hline
\end{tabular}

${ }^{*}$ Chemotherapy, trastuzumab, and/or lapatinib.

${ }^{\dagger}$ Liver and/or lung.

${ }^{\ddagger}$ Objective response or stable disease $\geq 24$ weeks.

increase, and pancreatitis). One patient died on study from cardiogenic shock; prior to enrolling in the present study, this patient had received a combination of fluorouracil, cyclophosphamide, and epirubicin in the adjuvant setting and trastuzumab followed by lapatinib in the advanced/metastatic setting.

Eleven patients discontinued the study and 18 patients permanently discontinued treatment with one or both study drugs due to AEs considered treatment-related. AEs resulted in temporary treatment discontinuations and/or dose reductions of one or both study drugs in 48 patients.

AEs related to measured LVEF declines were reported in 24 patients $(40 \%)$ during the study (Table 4). However, these were asymptomatic (CTCAE grade 1/2) in 18 patients $(30 \%)$; only $10 \%$ of patients exhibited symptoms related to LVEF declines. LVEF decline occurred more frequently in patients who had received prior treatment with anthracyclines alone or combined with trastuzumab (55\% and 50\%, respectively) compared with patients who had received neither type of agent or trastuzumab only (26\% and 0\%). Median LVEF for the whole group was $63 \%$ at baseline; during $\mathrm{C} 3, \mathrm{C} 5, \mathrm{C} 7$, and $\mathrm{C} 9$, and at the end of treatment, it was at or above the lower limit of normal (range: 55-60\%).

\section{Pharmacokinetics}

Mean dose-corrected, steady-state trough plasma concentrations (coefficient of variation) of sunitinib, the active metabolite SU12662, and total drug (sunitinib plus SU12662) were 53.5 (52\%), 26.7 (54\%), and $80.2(50 \%)$ $\mathrm{ng} / \mathrm{mL}$ on C3D1 $(\mathrm{n}=18)$; and $55.0(45 \%), 24.7(51 \%)$, and $79.7(46 \%) \mathrm{ng} / \mathrm{mL}$ on C5D1 $(\mathrm{n}=13)$, respectively.

\section{Effect of total-drug exposure on efficacy and safety} Among patients with trough plasma drug concentration measurements on C3D1 or C5D1, the ORR was higher in patients with total-drug trough concentrations above the median (higher-exposure sub-group) than below the median (lower-exposure sub-group; Table 5). SD rates were lower in the former than the latter PK sub-group. CBRs (defined in these analyses as percentages of patients with objective responses or $\mathrm{SD} \geq 12$ weeks) were similar in the two PK sub-groups. Median PFS was longer in the sub-group with higher exposure on C5D1 $(\mathrm{p}=0.013$; Table 5).

The effect of total-drug trough concentrations on C3D1 $(\mathrm{n}=29)$ and C5D1 $(\mathrm{n}=18)$ on the incidences of specific AEs reported in $\mathrm{C} 1-\mathrm{C} 4$ was also evaluated. Incidences of asthenia (any grade) and leukopenia (any grade and grade $3 / 4$ ) appeared to be similar or higher in the higher-exposure sub-group. Incidences of any grade and grade $3 / 4$ hypertension and thrombocytopenia appeared to be consistently higher in the higher-exposure sub-group. No lymphopenia was reported in either subgroup, and no consistent trends were observed with respect to the incidences of decreased ejection fraction or neutropenia reported as AEs. Correlative analyses showed moderate to strong correlations between total-drug trough concentrations and a number of key safety parameters (reduced neutrophil and leukocyte counts, elevated systolic or diastolic blood pressure, and reduced LVEF), particularly on C5D1 (Table 6).

\section{Patient-reported outcomes}

Mean changes from baseline in EORTC QLQ-C30 functional and symptom scores and in BR23 scores were analyzed. Overall, PROs appeared to be mixed in the study, with some functional domains and symptoms improving during treatment and others (particularly diarrhea) worsening.

Among EORTC QLQ-C30 functional scores, emotional function showed clinically meaningful improvement on 

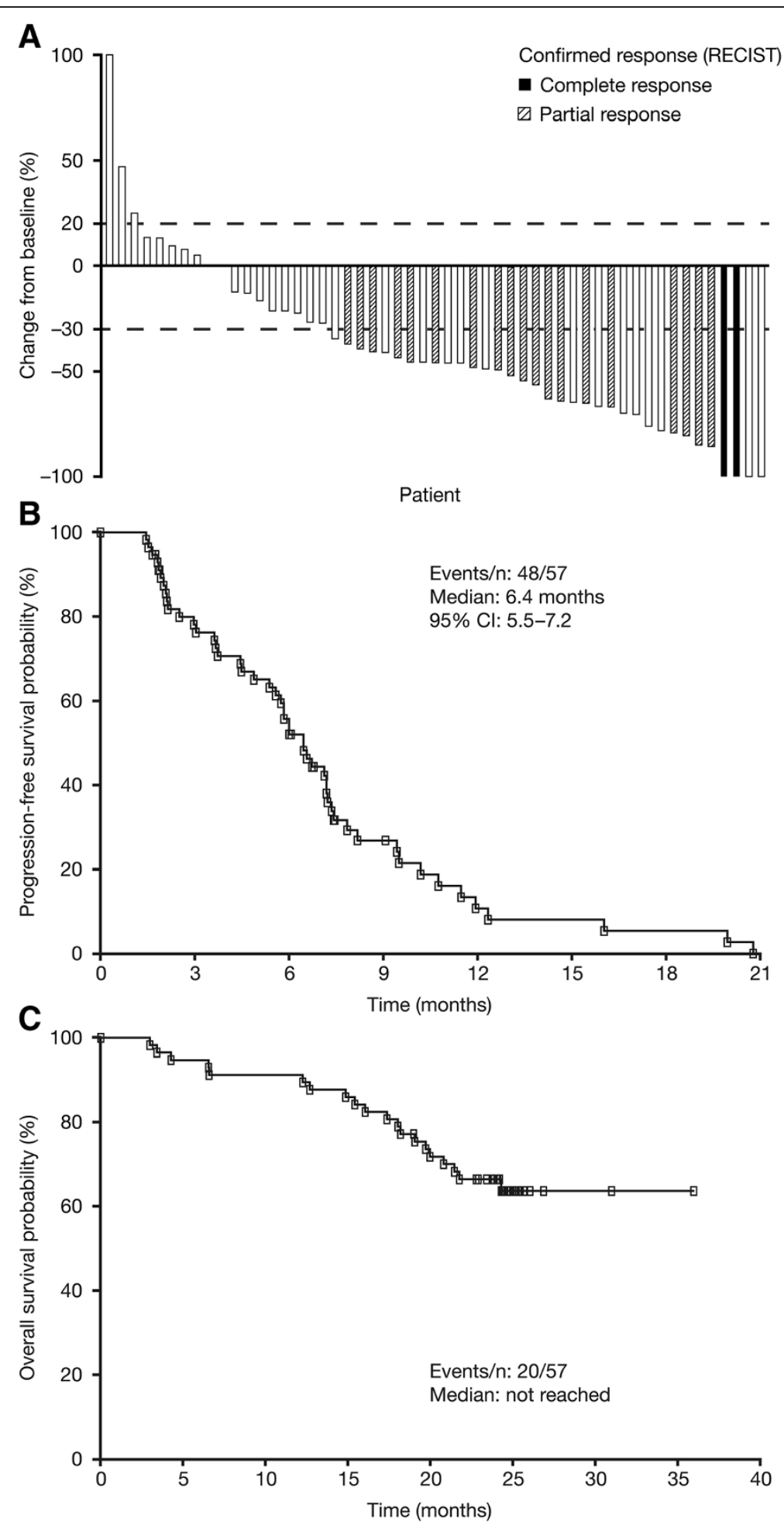

Figure 1 Antitumor activity of sunitinib plus trastuzumab. (A) Maximum reduction in target lesion size by patient, with confirmed responses based on RECIST indicated. Broken gray lines indicate cut-offs for progressive disease and partial responses. (B) and (C) Kaplan-Meier estimates of (B) progression-free survival and (C) overall survival. RECIST, Response Evaluation Criteria in Solid Tumors. 
Table 3 Non-hematologic adverse events (AEs) and hematologic laboratory abnormalities $(N=60)$

\begin{tabular}{|c|c|c|c|c|}
\hline \multirow{2}{*}{$\begin{array}{l}\text { AE or laboratory } \\
\text { abnormality }\end{array}$} & \multicolumn{4}{|c|}{ n (\%) } \\
\hline & Grade $1 / 2$ & Grade 3 & Grade 4 & $\begin{array}{c}\text { Any } \\
\text { grade }\end{array}$ \\
\hline \multicolumn{5}{|c|}{ Non-hematologic AEs of any cause occurring in $\geq 15 \%$ of patients } \\
\hline Fatigue/asthenia & $33(55)$ & $12(20)$ & 0 & $45(75)$ \\
\hline Diarrhea & $33(55)$ & $3(5)$ & 0 & $36(60)$ \\
\hline $\begin{array}{l}\text { Stomatitis, oral discomfort, } \\
\text { and related oral syndromes }\end{array}$ & $29(48)$ & $3(5)$ & 0 & $32(53)$ \\
\hline Dysgeusia & $27(45)$ & 0 & 0 & $27(45)$ \\
\hline Hypertension & $18(30)$ & $8(13)$ & 0 & $26(43)$ \\
\hline $\begin{array}{l}\text { Skin and subcutaneous } \\
\text { tissue disorders }\end{array}$ & $25(42)$ & 0 & 0 & $25(42)$ \\
\hline Vomiting & $19(32)$ & $2(3)$ & 0 & $21(35)$ \\
\hline Dyspepsia & $20(33)$ & 0 & 0 & $20(33)$ \\
\hline Epistaxis & $18(30)$ & $2(3)$ & 0 & $20(33)$ \\
\hline Nausea & $20(33)$ & 0 & 0 & $20(33)$ \\
\hline Headache & $17(28)$ & $2(3)$ & 0 & $19(32)$ \\
\hline Decreased appetite & $14(23)$ & $4(7)$ & 0 & $18(30)$ \\
\hline Dry skin & $14(23)$ & $1(2)$ & 0 & $15(25)$ \\
\hline Ejection fraction decreased & $10(17)$ & $3(5)$ & $1(2)$ & $14(23)$ \\
\hline Abdominal pain & $11(18)$ & 0 & 0 & $11(18)$ \\
\hline $\begin{array}{l}\text { Hand-foot syndrome and } \\
\text { related disorders }\end{array}$ & $8(13)$ & $3(5)$ & 0 & $11(18)$ \\
\hline Pyrexia & $11(18)$ & 0 & 0 & $11(18)$ \\
\hline Weight decreased & $11(18)$ & 0 & 0 & $11(18)$ \\
\hline Constipation & $10(17)$ & 0 & 0 & $10(17)$ \\
\hline Left ventricular dysfunction & $8(13)$ & $2(3)$ & 0 & $10(17)$ \\
\hline Insomnia & $8(13)$ & $1(2)$ & 0 & $9(15)$ \\
\hline Dyspnea & $8(13)$ & $1(2)$ & 0 & $9(15)$ \\
\hline
\end{tabular}

Hematologic laboratory abnormalities

\begin{tabular}{lcccc} 
Leukopenia & $46(77)$ & $4(7)$ & $1(2)$ & $51(85)$ \\
Anemia & $46(77)$ & $2(3)$ & 0 & $48(80)$ \\
Neutropenia & $36(60)$ & $9(15)$ & $1(2)$ & $46(77)$ \\
Lymphopenia & $36(60)$ & $6(10)$ & $1(2)$ & $43(72)$ \\
Thrombocytopenia & $34(57)$ & $6(10)$ & $3(5)$ & $43(72)$ \\
\hline
\end{tabular}

C5D1 and C7D1. Role functioning and global health status exhibited clinical meaningful worsening on C3D1 and C5D1. Among symptom scores, pain (C3D1 and C5D1) and insomnia (C5D1 and C7D1) showed improvement. Worsening was observed in fatigue (C3D1) and diarrhea (C3D1, C5D1, and C7D1). Among BR23 scores, improvement was observed in breast symptoms (C3D1, C5D1, and C7D1) and arm symptoms (C5D1). Sexual enjoyment (among those who reported being sexually active) and systemic therapy side effects worsened by C3D1. No other clinically meaningful changes in EORTC QLQ-C30 or BR23 scores were observed.
Table 4 LVEF decline* by prior treatment

\begin{tabular}{lcccc}
\hline & & \multicolumn{3}{c}{$\mathbf{n ~ ( \% )}$} \\
\cline { 3 - 5 } Prior treatment $^{\dagger}$ & $\mathbf{n}$ & Asymptomatic $^{\ddagger}$ & Symptomatic $^{\ddagger}$ & Total \\
\hline None & 19 & $5(26)$ & 0 & $5(26)$ \\
Trastzumab only & 4 & 0 & 0 & 0 \\
Anthracycline only & 11 & $5(45)$ & $5(19)^{\S}$ & $13(50)$ \\
Trastuzumab and & 26 & $8(31)$ & & $6(55)$ \\
anthracycline & & & $6(10)^{\mathbf{9}}$ & $24(40)$ \\
All patients & 60 & $18(30)$ &
\end{tabular}

Abbreviations: $A E$ adverse event, CTCAE Common Terminology Criteria for

Adverse Events, $L V E F$ left ventricular ejection fraction.

* Reported as an AE.

${ }^{\dagger}$ Trastuzumab and/or anthracycline.

${ }^{\ddagger}$ Asymptomatic, CTCAE grade 1/2; symptomatic, CTCAE grade 3/4.

${ }^{\S}$ One fatal event occurred (cardiogenic shock).

"Three of six of these patients discontinued the study due to LVEF decline.

\section{Discussion}

Sunitinib $37.5 \mathrm{mg}$ on a CDD schedule in combination with trastuzumab (weekly or 3-weekly) demonstrated substantial antitumor activity in patients with $A B C$, with an ORR of $37 \%$ and a CBR of $56 \%$. The null hypothesis that the ORR of the sunitinib - trastuzumab combination was no different than the historical trastuzumab ORR was therefore rejected. A 1-year survival rate of $91 \%$ was achieved, and median OS was not reached (survival was only followed for 2 years post-dose).

The ORR of the combination was greater than the $11 \%$ ORR reported in two previous studies of sunitinib monotherapy (administered at $50 \mathrm{mg} /$ day on Schedule $4 / 2$ or $37.5 \mathrm{mg} /$ day on a CDD schedule) in previously treated patients with $\mathrm{ABC}[13,32]$. In the current study, most responses $(71 \%)$ were noted in treatment-naïve patients and in patients who had received only prior adjuvant therapy. These patients achieved an ORR of $44 \%$, similar to that observed in an earlier trial of first-line bevacizumab plus trastuzumab (46\%) [21]. The high ORR obtained with the sunitinib-trastuzumab combination in patients with visceral disease (44\%) was also encouraging. These observations provide additional support for synergy between tumor-specific HER2-targeted and antiangiogenic therapies for aggressive disease, as predicted in preclinical studies (Pfizer Inc., data on file). In particular, the action of sunitinib on both vascular endothelial cells and pericytes $[7,8,33]$ as a result of dual targeting of VEGFR and PDGFR may complement HER2-targeting by trastuzumab, although trastuzumab resistance did not appear to be overcome in patients receiving the combination as second-line therapy.

In general, the sunitinib - trastuzumab combination appeared to have an acceptable safety profile that was broadly consistent with the profiles of both drugs administered as monotherapy $[13,32,34]$, with the majority of AEs being of mild to moderate severity. Dosing modifications were frequently used to manage AEs, with $80 \%$ 
Table 5 Effect of total-drug* exposure on antitumor activity

\begin{tabular}{|c|c|c|c|c|}
\hline \multirow[b]{2}{*}{ Efficacy parameter $^{\dagger}$} & \multicolumn{2}{|c|}{ C3D1 } & \multicolumn{2}{|c|}{ C5D1 } \\
\hline & No. of evaluable patients & No. with parameter (\%) & No. of evaluable patients & No. with parameter (\%) \\
\hline \multicolumn{5}{|l|}{ Objective response } \\
\hline$<$ Median trough concentation & 14 & $4(29)$ & 9 & $3(33)$ \\
\hline$\geq$ Median trough concentation & 15 & $10(67)$ & 9 & $7(78)$ \\
\hline \multicolumn{5}{|l|}{ Stable disease } \\
\hline$<$ Median trough concentation & 14 & $8(57)$ & 9 & $6(67)$ \\
\hline$\geq$ Median trough concentation & 15 & $3(20)$ & 9 & $2(22)$ \\
\hline \multicolumn{5}{|l|}{ Clinical benefit ${ }^{\ddagger}$} \\
\hline$<$ Median trough concentation & 14 & $11(79)$ & 9 & $9(100)$ \\
\hline$\geq$ Median trough concentation & 15 & $13(87)$ & 9 & $9(100)$ \\
\hline \multicolumn{5}{|l|}{ Median PFS $(95 \% \mathrm{Cl})$, months } \\
\hline$<$ Median trough concentation & 14 & $6.6(4.9-9.5)$ & 9 & $7.2(6.0-7.3)$ \\
\hline$\geq$ Median trough concentation & 15 & $7.3(6.4-10.2)^{\S}$ & 9 & $9.5(8.1-10.7)^{q}$ \\
\hline
\end{tabular}

Abbreviations: $C$ cycle, D day, PFS progression-free survival.

*Sunitinib + SU12662.

${ }^{\dagger}$ By trough concentration of total drug on C3D1 or C5D1 as indicated.

${ }^{\ddagger}$ Patients with objective responses or stable disease $\geq 12$ weeks.

§Log-rank $p=0.879$.

"Log-rank $p=0.013$.

of patients having temporary treatment discontinuations and/or dose reductions of one or both study drugs due to AEs.

Cardiac dysfunction is a known side effect of trastuzumab, with reported incidences of $3-7 \%$ when given as monotherapy and $27 \%$ when administered with anthracycline-containing chemotherapy [35]. Cardiac dysfunction has also been associated with sunitinib treatment, with reported incidences of $11-19 \%$ in patients with RCC or GIST [36-38]. Given that the drugs were used in combination in this study, LVEF was monitored frequently. Forty percent of patients $(24 / 60)$ experienced AEs related to measured LVEF declines, although in the majority of these patients $(75 \%)$ the

Table 6 Correlation between trough concentration of total drug* and change in laboratory parameters

\begin{tabular}{lcc}
\hline Laboratory parameter $^{\dagger}$ & \multicolumn{2}{c}{ Pearson correlation coefficient (R) } \\
\cline { 2 - 3 } & C3D1 $(\boldsymbol{n}=\mathbf{2 9})$ & C5D1 $(\boldsymbol{n}=\mathbf{1 8})$ \\
\hline Absolute neutrophil count & 0.15 & -0.64 \\
Leukocyte count & 0.20 & -0.79 \\
Lymphocyte count & 0.12 & -0.21 \\
Thrombocyte count & -0.33 & -0.40 \\
Systolic blood pressure & 0.18 & 0.68 \\
Diastolic blood pressure & 0.06 & 0.51 \\
Ejection fraction & -0.61 & -0.21 \\
\hline
\end{tabular}

Abbreviations: $C$ cycle, $D$ day.

*Sunitinib + SU12662.

${ }^{\dagger}$ Based on percent change from baseline.

${ }^{*}$ Weak correlation, $|\mathrm{R}|<0.50$; moderate correlation, $0.50 \leq|\mathrm{R}|<0.75$; strong

correlation, $|R| \geq 0.75$. events were asymptomatic (CTCAE grade $1 / 2$ ), with measured changes in LVEF during the events being between $-4 \%$ and $-37 \%$ relative to baseline. Pre-exposure to anthracyclines appeared to be a major factor contributing to cardiac dysfunction: 19 of the 24 patients with LVEF-related AEs overall (79\%) and all six with symptomatic LVEF-related events had received prior anthracycline treatment, either with or without prior trastuzumab therapy. Of the 23 patients in the study who had not received prior anthracyclines, only five experienced LVEF-related AEs (22\%). This rate of LVEF decline following prior anthracycline treatment was consistent with that reported in other studies using trastuzumab [2,22]. Median baseline LVEF was similar between the 37 patients who had received prior anthracyclines and the 23 who had not (61\% vs. $64 \%)$.

In total, five patients (8\%) discontinued the present study for reasons related to cardiac dysfunction: three discontinued due to measured LVEF declines (ranging from $-18 \%$ to $-30 \%$ relative to baseline), one due to acute heart failure (with an LVEF decline of 27\%), and one due to asthenia, cardiac insufficiency, and dyspnea (with an LVEF decline of 37\%). Additionally, as noted above, one patient died due to cardiogenic shock (with a change in LVEF from $54 \%$ at screening to $23 \% 3$ days prior to death). In the majority of the 24 patients with LVEF-related AEs (67\%), the events resolved either spontaneously or following temporary or permanent discontinuation of trastuzumab (and, in one case, sunitinib as well), in contrast to cardiac dysfunction associated with anthracycline treatment, which is usually irreversible 
[39]. Nevertheless, the results of the present study, including the high rate of grade 3/4 cardiotoxicity in anthracycline-exposed patients, indicate that great caution along with proactive cardiac monitoring and management of cardiotoxicity by treatment interruption/ discontinuation are critical when using a drug combination such as that tested in this study.

Steady-state concentrations of sunitinib, the active metabolite SU12662, and total drug were consistent with those obtained with single-agent sunitinib administered at $50 \mathrm{mg} /$ day on Schedule 4/2 to patients with MBC [13]. Pharmacokinetic evaluations suggested that no clinically relevant drug - drug interactions had occurred. In addition, antitumor response appeared to correlate with plasma drug exposure: ORR and PFS appeared to be greater in patients with higher plasma drug exposures. Correlations were also observed between plasma drug exposures and several key safety parameters.

In conclusion, sunitinib on a CDD schedule in combination with trastuzumab (weekly or 3-weekly) demonstrated antitumor activity in patients with HER2-positive $A B C$, particularly in those who were treatment-naïve or had only received prior adjuvant treatment. Sunitinib plus trastuzumab had acceptable safety and tolerability in patients with $\mathrm{ABC}$ who had not received prior anthracycline therapy. The regimen is not being developed further, however, based on disappointing results obtained in four phase III studies of sunitinib in patients with ABC [26-29]. Nevertheless, the results obtained in this study contribute to the field of antiangiogenesis by adding to the evidence supporting a beneficial effect of targeting both the VEGF and HER2 pathways and by providing a platform for further exploration with other agents that may lead to benefit in specific patient populations.

\section{Competing interests}

This study was sponsored by Pfizer Inc. T. Bachelot has had consultant/ advisory relationships with and received honoraria from Novartis and Roche and has received research funding from Roche. S. Verma has had consultant/ advisory relationships with and received honoraria from Roche and Pfizer, and has received research funding from Roche. X. Pivot has had consultant/ advisory relationships with Roche, GlaxoSmithKline, and Novartis, and received honoraria from Roche and GlaxoSmithKline. M. F. Kozloff has received honoraria from Pfizer and Genentech. C. Prady has received honoraria from Roche. X. Huang, R. Khosravan, Z. Wang, V. Tassell, and K. A. Kern are/were employees of Pfizer and hold/held Pfizer stock. R. Cesari is an employee of Pfizer. J.-Y. Blay has had consultant/advisory relationships with and received honoraria from Pfizer, Novartis, Roche, GlaxoSmithKline, and Pharmamar, and has received research funding from Novartis, Roche, and Pharmamar. The other authors have no potential conflicts of interest to disclose

\section{Authors' contributions}

J-YB contributed to the conception and design of the study. TB, JAG-S, SV, $M G, C P$, and $A L$ participated in collection and assembly of the data. TB, XP, $Z W, M F K, C P, X H, R K, R C, V T, K A K$, and J-YB participated in data analysis and interpretation. All authors participated in drafting the manuscript and/or revising it critically for important intellectual content, and all approved the final version.

\section{Acknowledgments}

We thank the participating patients and their families, as well as the network of investigators, research nurses, study coordinators, and operations staff. In particular, we would like to acknowledge our co-investigators, Intidhar Labidi-Galy, Isabelle Ray-Coquard, and Olivier Tredan (Centre Léon-Bérard, Lyon, France) for their participation in this study. This study was sponsored by Pfizer Inc. Medical writing support was provided by Wendy Sacks at ACUMED $^{\circledR}$ (New York, NY, USA), which was funded by Pfizer Inc.

\section{Author details}

'EORTC, Soft Tissue and Bone Sarcoma Group, Centre Léon-Bérard and Université Claude Bernard, Lyon, France. ${ }^{2}$ Hospital Clinico San Carlos, Madrid, Spain. ${ }^{3}$ Sunnybrook Health Sciences Centre, Odette Cancer Centre, Toronto, Canada. ${ }^{4}$ Medical Oncology, René Huguenin Cancer Centre, Saint Cloud, France. ${ }^{5}$ Hôpital Jean Minjoz, Besançon, France. ${ }^{6}$ University of Chicago, Chicago, and Ingalls Memorial Hospital, Harvey, IL, USA. ${ }^{7}$ Centre intégré de cancérologie de la Montérégie, CSSS Champlain-Charles-Lemoyne, Greenfield Park, Quebec, Canada. ${ }^{8}$ Pfizer Oncology, La Jolla, CA, USA. ${ }^{9}$ Pfizer Oncology, New York, NY, USA. ${ }^{10}$ Pfizer Oncology, Milan, Italy.

${ }^{11}$ INCLIVA-Servicio de Oncología Médica, Hospital Clínico Universitario de Valencia, Valencia, Spain. ${ }^{12}$ Previous employee of Pfizer; current affiliation: Eisai Inc., Woodcliff Lake, NJ, USA. ${ }^{13}$ Previous employee of Pfizer; current affiliation: Aragon Pharmaceuticals Inc., San Diego, CA, USA. ${ }^{14}$ Léon Bérard Comprehensive Cancer Centre, Université Claude Bernard Lyon I, 28 rue Laennec, F-69008 Lyon, France.

Received: 9 December 2013 Accepted: 20 February 2014 Published: 7 March 2014

\section{References}

1. Vogel CL, Cobleigh MA, Tripathy D, Gutheil JC, Harris LN, Fehrenbacher L, Slamon DJ, Murphy M, Novotny WF, Burchmore M, Shak S, Stewart SJ, Press $M$ : Efficacy and safety of trastuzumab as a single agent in first-line treatment of HER2-overexpressing metastatic breast cancer. J Clin Oncol 2002, 20(3):719-726.

2. Cobleigh MA, Vogel CL, Tripathy D, Robert NJ, Scholl S, Fehrenbacher L, Wolter JM, Paton V, Shak S, Lieberman G, Slamon DJ: Multinational study of the efficacy and safety of humanized anti-HER2 monoclonal antibody in women who have HER2-overexpressing metastatic breast cancer that has progressed after chemotherapy for metastatic disease. J Clin Oncol 1999, 17(9):2639-2648.

3. Tripathy D, Slamon DJ, Cobleigh M, Arnold A, Saleh M, Mortimer JE, Murphy M, Stewart SJ: Safety of treatment of metastatic breast cancer with trastuzumab beyond disease progression. J Clin Oncol 2004, 22(6):1063-1070.

4. Slamon DJ, Leyland-Jones B, Shak S, Fuchs H, Paton V, Bajamonde A, Fleming T, Eiermann W, Wolter J, Pegram M, Baselga J, Norton L: Use of chemotherapy plus monoclonal antibody against HER2 for metastatic breast cancer that overexpresses HER2. N Engl J Med 2001, 344(11):783-792.

5. Morrow PKH, Zambrana F, Esteva FJ: Advances in systemic therapy for HER2-positive metastatic breast cancer. Breast Cancer Res 2009, 11(4):207-216.

6. Metro G, Mottolese M, Fabi A: HER-2-positive metastatic breast cancer: trastuzumab and beyond. Exp Op Pharmacother 2008, 9(15):2583-2601.

7. Abrams TJ, Lee LB, Murray LJ, Pryer NK, Cherrington JM: SU11248 inhibits KIT and platelet-derived growth factor receptor beta in preclinical models in human small cell lung cancer. Mol Cancer Ther 2003, 2(5):471-478.

8. Mendel DB, Laird AD, Xin X, Louie SG, Christensen JG, Li G, Schreck RE, Abrams TJ, Ngai TJ, Lee LB, Murray LJ, Carver J, Chan E, Moss KG, Haznedar JO, Sukbuntherng J, Blake RA, Sun L, Tang C, Miller T, Shirazian S, McMahon G, Cherrington JM: In vivo antitumor activity of SU11248, a novel tyrosine kinase inhibitor targeting vascular endothelial growth factor and plateletderived growth factor receptors: determination of a pharmacokinetic/ pharmacodynamic relationship. Clin Cancer Res 2003, 9(1):327-337.

9. O'Farrell AM, Abrams TJ, Yuen HA, Ngai TJ, Louie SG, Yee KW, Wong LM, Hong W, Lee LB, Town A, Smolich BD, Manning WC, Murray L, Heinrich MC, Cherrington JM: SU11248 is a novel FLT3 tyrosine kinase inhibitor with potent activity in vitro and in vivo. Blood 2003, 101(9):3597-3605.

10. Murray LJ, Abrams TJ, Long KR, Ngai TJ, Olson LM, Hong W, Keast PK, Brassard JA, O'Farrell AM, Cherrington JM, Pryer NK: SU11248 inhibits tumor 
growth and CSF-1R-dependent osteolysis in an experimental breast cancer bone metastasis model. Clin Exp Metastasis 2003, 20(8):757-766.

11. Kim DW, JO YS, Jung HS, Chung HK, Song JH, Park KC, Park SH, Hwang JH, Rha SY, Kweon GR, Lee SJ, Jo KW, Shong M: An orally administered multitarget tyrosine kinase inhibitor, SU11248, is a novel potent inhibitor of thyroid oncogenic RET/papillary thyroid cancer kinases. J Clin Endocrinol Metab 2006, 91(10):4070-4076.

12. Kodera Y, Katanasaka Y, Kitamura Y, Tsuda H, Nishio K, Tamura T, Koizumi F: Sunitinib inhibits lymphatic endothelial cell functions and lymph node metastasis in a breast cancer model through inhibition of vascular endothelial growth factor receptor 3. Breast Cancer Res 2011, 13(3):R66.

13. Burstein HJ, Elias AD, Rugo HS, Cobleigh MA, Wolff AC, Eisenberg PD, Lehman M, Adams BJ, Bello CL, DePrimo SE, Baum CM, Miller KD: Phase II study of sunitinib malate, an oral multitargeted tyrosine kinase inhibitor, in patients with metastatic breast cancer previously treated with an anthracycline and a taxane. J Clin Oncol 2008, 26(11):1810-1816.

14. Escudier B, Roigas J, Gillessen S, Harmenberg U, Srinivas S, Mulder SF, Fountzilas G, Peschel C, Flodgren P, Maneval EC, Chen I, Vogelzang NJ: Phase II study of sunitinib administered in a continuous once-daily dosing regimen in patients with cytokine-refractory metastatic renal cell carcinoma. J Clin Oncol 2009, 27(25):4068-4075.

15. Barrios CH, Hernandez-Barajas D, Brown MP, Lee SH, Fein L, Liu JH, Hariharan S, Martell BA, Yuan J, Bello A, Wang Z, Mundayat R, Rha SY: Phase II trial of continuous once-daily dosing of sunitinib as first-line treatment in patients with metastatic renal cell carcinoma. Cancer 2012, 118(5):1252-1259.

16. George S, Blay JY, Casali PG, Le Cesne A, Stephenson P, Deprimo SE, Harmon CS, Law CN, Morgan JA, Ray-Coquard I, Tassell V, Cohen DP, Demetri GD: Clinical evaluation of continuous daily dosing of sunitinib malate in patients with advanced gastrointestinal stromal tumour after imatinib failure. Eur J Cancer 2009, 45(11):1959-1968.

17. Raymond E, Dahan L, Raoul JL, Bang YJ, Borbath I, Lombard-Bohas C, Valle J, Metrakos P, Smith D, Vinik A, Chen JS, Hörsch D, Hammel P, Wiedenmann B, Van Cutsem E, Patyna S, Lu DR, Blanckmeister C, Chao R, Ruszniewski P: Sunitinib malate for the treatment of pancreatic neuroendocrine tumors. N Engl J Med 2011, 364(6):501-513. Erratum in: N Engl J Med 2011, 364(11):1082.

18. Finkenzeller G, Weindel K, Zimmermann W, Westin G, Marmé D: Activated Neu/ErbB-2 induces expression of the vascular endothelial growth factor gene by functional activation of the transcription factor $\mathrm{Sp} 1$. Angiogenesis 2004, 7(1):59-68.

19. Konecny GE, Meng YG, Untch M, Wang HJ, Bauerfeind I, Epstein M, Stieber P, Vernes JM, Gutierrez J, Hong K, Beryt M, Hepp H, Slamon DJ, Pegram MD: Association between HER-2/neu and vascular endothelial growth factor expression predicts clinical outcome in primary breast cancer patients. Clin Cancer Res 2004, 10(5):1706-1716.

20. Klos KS, Wyszomierski SL, Sun M, Tan M, Zhou X, Li P, Yang W, Yin G Hittelman WN, Yu D: ErbB2 increases vascular endothelial growth factor protein synthesis via activation of mammalian target of rapamycin/ p7056K leading to increased angiogenesis and spontaneous metastasis of human breast cancer cells. Cancer Res 2006, 66(4):2028-2037.

21. Pegram M, Chan D, Dichmann RA, Tan-Chiu E, Yeon C, Durna L, Lin LS, Slamon D: Phase II combined biological therapy targeting the HER2 protooncogene and the vascular endothelial growth factor using trastuzumab (T) and bevacizumab (B) as first line treatment of HER2-amplified breast cancer. Breast Cancer Res Treat 2006, 100:3039. abstract.

22. Baselga J, Carbonell X, Castaneda-Soto NJ, Clemens M, Green M, Harvey V, Morales S, Barton C, Ghahramani P: Phase II study of efficacy, safety, and pharmacokinetics of trastuzumab monotherapy administered on a 3-weekly schedule. J Clin Oncol 2005, 23(10):2162-2171.

23. Gianni L, Romieu G, Lichinitser M, Serrano S, Mansutti M, Pivot X, Smirnova I, Moliterni A, Andre F, Chan A, Lipatov O, Chan S, Wardley A, Greil R, Provencher $L$, Moore N, Prot S, Semiglazov V: First results of AVEREL, a randomized phase III trial to evaluate bevacizumab (BEV) in combination with trastuzumab $(\mathrm{H})+$ docetaxel $(\mathrm{DOC})$ as first-line therapy for HER2positive locally recurrent/ metastatic breast cancer (LR/mBC). Cancer Res 2011, 71(24 Suppl):abstract S4-8.

24. Bergers G, Song S, Meyer-Morse N, Bergsland E, Hanahan D: Benefits of targeting both pericytes and endothelial cells in the tumor vasculature with kinase inhibitors. J Clin Invest 2003, 111(9):1287-1295.

25. Potapova O, Laird AD, Nannini MA, Barone A, Li G, Moss KG, Cherrington $J M$, Mendel DB: Contribution of individual targets to the antitumor efficacy of the multitargeted receptor tyrosine kinase inhibitor SU11248. Mol Cancer Ther 2006, 5(5):1280-1289.

26. Bergh J, Bondarenko IM, Lichinitser MR, Liljegren A, Greil R, Voytko NL, Makhson AN, Cortes J, Lortholary A, Bischoff J, Chan A, Delaloge S, Huang X, Kern KA, Giorgetti C: First-line treatment of advanced breast cancer with sunitinib in combination with docetaxel versus docetaxel alone: results of a prospective, randomized phase III study. J Clin Oncol 2012, 30(9):921-929.

27. Robert NJ, Saleh MN, Paul D, Generali D, Gressot L, Copur MS, Brufsky AM, Minton SE, Giguere JK, Smith JW 2nd, Richards PD, Gernhardt D, Huang X, Liau KF, Kern KA, Davis J: Sunitinib plus paclitaxel versus bevacizumab plus paclitaxel for first-line treatment of patients with advanced breast cancer: a phase III, randomized, open-label trial. Clin Breast Cancer 2011, 11(2):82-92.

28. Barrios CH, Liu MC, Lee SC, Vanlemmens L, Ferrero JM, Tabei T, Pivot $X$, Iwata H, Aogi K, Lugo-Quintana R, Harbeck N, Brickman MJ, Zhang K, Kern KA, Martin M: Phase III randomized trial of sunitinib versus capecitabine in patients with previously treated HER2-negative advanced breast cancer. Breast Cancer Res Treat 2010, 121(1):121-131.

29. Crown JP, Diéras V, Staroslawska E, Yardley DA, Bachelot T, Davidson N, Wildiers H, Fasching PA, Capitain O, Ramos M, Greil R, Cognetti F, Fountzilas G, Blasinska-Morawiec M, Liedtke C, Kreienberg R, Miller WH Jr, Tassell V, Huang X, Paolini J, Kern KA, Romieu G: Phase III trial of sunitinib in combination with capecitabine versus capecitabine monotherapy for the treatment of patients with pretreated metastatic breast cancer. J Clin Oncol 2013, 31(23):2870-2878

30. Therasse P, Arbuck SG, Eisenhauer EA, Wanders J, Kaplan RS, Rubinstein L, Verweij J, Van Glabbeke M, van Oosterom AT, Christian MC, Gwyther SG: New guidelines to evaluate the response to treatment in solid tumors: European Organisation for Research and Treatment of Cancer, National Cancer Institute of the United States, National Cancer Institute of Canada. J Natl Cancer Inst 2000, 92(3):205-216.

31. Osoba D, Rodrigues G, Myles J, Zee B, Pater J: Interpreting the significance of changes in health-related quality-of-life scores. J Clin Oncol 1998, 16(1):139-144

32. Demetri GD, Garrett $C R$, Schöffski $P$, Shah MH, Verweij J, Leyvraz S, Hurwitz HI, Pousa AL, Le Cesne A, Goldstein D, Paz-Ares L, Blay JY, McArthur GA, Xu QC, Huang X, Harmon CS, Tassell V, Cohen DP, Casali PG: Complete longitudinal analyses of the randomized, placebo-controlled, phase III trial of sunitinib in patients with gastrointestinal stromal tumor following imatinib failure. Clin Cancer Res 2012, 18(11):3170-9.

33. Yao VJ, Sennino B, Davis RB, Christensen J, Hu-Lowe D, Roberts G, McDonald DM: Combined anti-VEGFR and anti-PDGFR actions of sunitinib on blood vessels in preclinical tumor models. European Journal of Cancer Supplements 2006, 4(12):27-28.

34. Genentech, Inc: Herceptin (trastuzumab) prescribing information. 2010. Available at: www/gene.com/gene/products/information/pdf/herceptin-prescribing.pdf

35. Seidman A, Hudis C, Pierri MK, Shak S, Paton V, Ashby M, Murphy M, Stewart SJ, Keefe D: Cardiac dysfunction in the trastuzumab clinical trials experience. J Clin Oncol 2002, 20(5):1215-1221.

36. Chu TF, Rupnick MA, Kerkela R, Dallabrida SM, Zurakowski D, Nguyen L, Woulfe K, Pravda E, Cassiola F, Desai J, George S, Morgan JA, Harris DM, Ismail NS, Chen JH, Schoen FJ, Van den Abbeele AD, Demetri GD, Force T, Chen $\mathrm{MH}$ : Cardiotoxicity associated with tyrosine kinase inhibitor sunitinib. Lancet 2007, 370(9604):2011-2019

37. Di Lorenzo G, Autorino R, Bruni G, Cartenì G, Ricevuto E, Tudini M, Ficorella C, Romano C, Aieta M, Giordano A, Giuliano M, Gonnella A, De Nunzio C, Rizzo M, Montesarchio V, Ewer M, De Placido S: Cardiovascular toxicity following suntinib therapy in metastatic renal cell carcinoma: a multicentre analysis. Ann Oncol 2009, 20(9):1535-1542.

38. Ewer MS, Suter TM, Lenihan DJ, Niculescu L, Breazna A, Demetri GD, Motzer RJ: Cardiovascular adverse events in a pooled analysis of 1090 patients from phase III sunitinib trials. Ann Oncol 2010, 21 (suppl. 8):viii 165. ${ }^{2}$ (abstract 506P).

39. Senkus $E$, Jassem J: Cardiovascular effects of systemic cancer treatment. Cancer Treat Rev 2011, 37(4):300-311.

doi:10.1186/1471-2407-14-166

Cite this article as: Bachelot et al:: Sunitinib in combination with trastuzumab for the treatment of advanced breast cancer: activity and safety results from a phase II study. BMC Cancer 2014 14:166. 